\title{
Co-administration of a Rhododendron tomentosum extract does not affect mercury tissue concentrations and excretion rate in methylmercury-treated adult male rats
}

\author{
${\text { Guillaume Pelletier }{ }^{*} \text { (B), Yong-Lai Feng }}^{2}$, Karen Leingartner ${ }^{1}$ and Paleah Black ${ }^{1,3}$
}

\begin{abstract}
Objectives: Consumption of fish/seafood is clearly linked to higher mercury levels in human tissue samples. However, correlations between methylmercury (MeHg) intakes calculated from dietary surveys and mercury body burdens are usually weak and can vary across populations. Different factors may affect MeHg absorption, distribution, metabolism and excretion, including co-exposures to phytochemicals and antibiotics, which were shown to affect mercury body burdens in rodents. Based on the observation that rat pups developmentally exposed to MeHg and a Rhododendron tomentosum extract (Labrador Tea) presented significantly higher blood mercury levels at weaning compared to pups exposed to $\mathrm{MeHg}$ alone, the modulation of $\mathrm{MeHg}$ toxicokinetics by Labrador Tea was further investigated in adult rats.

Results: Total mercury levels were quantified in the blood, liver, kidney and feces of adult male rats exposed to MeHg $(1.2 \mathrm{mg} / \mathrm{kg}$ bodyweight/day, for 3 weeks) administered either alone or in combination with Labrador Tea (100 mg/kg bodyweight/day) or with an antibiotics cocktail (to inhibit MeHg demethylation by gut bacteria). While the reduced fecal excretion and higher blood mercury levels expected from antibiotics-treated rats were observed, mercury levels in samples from Labrador Tea-treated rats were not significantly different from those measured in samples from rats exposed to MeHg alone.
\end{abstract}

Keywords: Rat, Co-exposure, Methylmercury, Labrador Tea, Rhododendron tomentosum, Antibiotics, Gut microbiota

\section{Introduction}

Although epidemiology studies clearly link increased mercury levels in human tissue samples to fish and seafood consumption, correlation coefficients between estimated $\mathrm{MeHg}$ dietary intakes and body burdens are usually weak, ranging from 0.3 to 0.4 [1, 2]. These relatively weak correlations have been attributed to mercury quantification issues, dietary survey imprecisions, recall biases $[2,3]$, impaired liver functions $[4,5]$, genetic

\footnotetext{
*Correspondence: Guillaume.Pelletier@canada.ca

${ }^{1}$ Hazard Identification Division, Environmental Health Science and Research Bureau, Health Canada, Environmental Health Centre, 50 Colombine Driveway, P.L. 0803B, Tunney's Pasture, Ottawa, ON K1A 0K9, Canada

Full list of author information is available at the end of the article
}

polymorphisms [6, 7], cooking methods $[8,9]$, and dietary interactions $[6,8-12]$. A better understanding of the factors affecting $\mathrm{MeHg}$ absorption, distribution, metabolism and excretion may contribute to a refinement of risk assessments, regulatory guidelines and mitigation strategies.

Methylmercury present in food (or excreted in bile) is almost entirely absorbed (or reabsorbed) in the gut [13]. However, a fraction of $\mathrm{MeHg}$ escapes enterohepatic cycling through demethylation in the gut lumen, which results in the production of poorly absorbed inorganic mercury [14]. Gut bacteria play an important role in this process, as illustrated by the slower elimination of $\mathrm{MeHg}$ observed in germ-free or antibiotic-treated rodents [1517]. The gut microbiome can also be affected by diet [18], as commonly consumed phytochemicals can present 
bactericidal or bacteriostatic properties in vitro $[19,20]$. Interestingly, consumption of black tea has been shown to affect the human gut microflora [21], and volunteers who ate fish and drank tea presented higher blood mercury concentrations than volunteers who only ate fish in a controlled human exposure study [22].

We previously reported that male and female rat pups developmentally exposed to MeHg and Labrador Tea (an antioxidant-rich Rhododendron tomentosum decoction consumed in Canadian Arctic communities) presented significantly higher blood mercury levels at weaning compared to pups exposed to the same $\mathrm{MeHg}$ dose administered alone [23]. In this follow-up study, adult male rats were exposed to the same daily dose of Labrador Tea or to an antibiotics cocktail (a positive control for gut bacteria inhibition) for 4 weeks (days 1 to 28), with or without concomitant daily exposure to $\mathrm{MeHg}$ for 3 weeks (days 8 to 28). At the end of the exposure period, total mercury concentrations in the blood, liver, kidney and feces of MeHg-treated rats co-exposed to Labrador Tea or antibiotics were compared to those measured in rats exposed to $\mathrm{MeHg}$ alone.

\section{Main text \\ Methods \\ Materials \\ Rhododendron tomentosum ssp. subarcticum collec- tion and characterization of the ethanolic extract were described by Black et al. [24]. The same freeze-dried extract (Labrador Tea) conserved under nitrogen gas in amber vials at $-20{ }^{\circ} \mathrm{C}$ was used to dose rat pups in a previous study [23] and adult rats in this study. The corn oil (Mazola brand, ACH foods, Memphis, TN, USA) and cookies (Teddy Graham, Nabisco, Toronto, ON, Canada) were purchased from a local grocery store. Unless other- wise stated, reagents were purchased from Sigma-Aldrich (Oakville, ON, Canada).}

\section{Animal treatment}

Experimental procedures were approved by Health Canada's Institutional Animal Care Committee. SpragueDawley male rats (7-8 weeks old) were purchased from Charles River Laboratories (St. Constant, QC, Canada) and housed individually in Health Guard ${ }^{\mathrm{R}}$ cages (Research Equipment Co., Bryant, TX, USA). They were allowed to acclimatize to the facility $\left(22 \pm 1{ }^{\circ} \mathrm{C}, 50 \pm 10 \%\right.$ humidity and 12-h [7:00 a.m. to 7:00 p.m.] light cycle) for at least 10 days. Teklad 2014 rodent diet (Harlan Laboratories, Indianapolis, IN, USA) and water were provided ad libitum. Rats were also trained to accept a cookie used for dosing.

Seven rats were randomly assigned to each of the following treatment groups: control, Labrador Tea
(100 mg/kg bw/day), antibiotics (neomycin [2 g/L], streptomycin $[2 \mathrm{~g} / \mathrm{L}]$ and penicillin $[2 \mathrm{~g} / \mathrm{L}]$, in drinking water), $\mathrm{MeHg}$ (1.2 mg/kg bw/day), MeHg + Labrador Tea and $\mathrm{MeHg}+$ antibiotics. Rats were weighed daily and water bottles changed twice a week. Rats were exposed to Labrador Tea and antibiotics from exposure day 1 to 28 and to $\mathrm{MeHg}$ from exposure day 8 to 28 . Weight-adjusted volumes of Labrador Tea dissolved in $100 \%$ ethanol were applied to cookies that were allowed to dry overnight in a fume hood. $\mathrm{MeHg}$ dissolved in corn oil was added to cookies (or to cookies containing Labrador Tea). To ensure uniform caloric intake, all rats received a sweet cookie (exposure day 1 to 7 ) or a sweet cookie laced with a weight-adjusted volume of corn oil (1.0 mL/kg bodyweight, exposure day 8 to 28$)$.

Feces samples were collected on the 28th day of exposure and rats were sacrificed under isoflurane anaesthesia on the following morning. Blood was drawn from the aorta, organs were inspected and the liver and kidneys were weighed. Hematological parameters and enzymatic activities in liver S9 extracts were measured as described by Poon et al. [25, 26]. Serum IgE, IgG, IgA and IgM levels were measured using ELISA Test Kits (GenWay Biotech Inc, San Diego, CA, USA) according to the manufacturer's instructions.

\section{Mercury quantification in rat tissues}

Total mercury measurements in blood and lyophilised kidney, liver and feces were performed by Prairie Diagnostic Services Inc. (Saskatoon, SK, Canada). Samples were digested in nitric acid in a Microwave Accelerated Reaction System (MARS-5, CEM, Matthews, NC, USA) and total mercury was quantified by inductivelycoupled plasma mass spectrometry (ICAP Q ICP-MS, Thermo Scientific, Waltham, MA, USA) as previously described [27, 28].

\section{Statistical analysis}

All raw data are included in the Additional file 1. Datasets satisfying normality and homoscedasticity assumptions (Shapiro-Wilk's test and Brown-Forsythe's test) were analysed by one-way ANOVA followed by Dunnett post hoc test, using SigmaPlot 11.2 (Systat Software Inc., Chicago, IL, USA). Otherwise, datasets were log-transformed and analysed using Kruskal-Wallis ANOVA followed by Dunnett post hoc test on ranks if they still failed to satisfy normality and homoscedasticity assumptions. Mercury tissue concentrations in Labrador Tea or antibiotics-treated rats were compared to the control or $\mathrm{MeHg}$ treatment group, as appropriate. 


\section{Results}

None of the treatment significantly affected male rat weight gains (Table 1) or resulted in overt sign of toxicity over the dosing period. Beside kidney cysts observed in two control rats and in one rat from the $\mathrm{MeHg}+\mathrm{Lab}-$ rador Tea treatment group, no other gross organ abnormality was observed at necropsy. Although the overall kidney cyst rate (3/42 rats or $7 \%$ ) was high compared to spontaneous kidney cysts reported in 2-year old male rats from five different species (5-12\%) [29], these cysts were not considered treatment-related as they were observed mainly in control rats. Lower relative liver weights accompanied by increased BROD, EROD and PROD activities were observed in the antibiotics treatment group. Both absolute and relative liver weights were significantly lower in the $\mathrm{MeHg}+$ antibiotics treatment group, but only BROD activity was significantly increased (Table 1).

Co-exposures to Labrador Tea and antibiotics did not significantly interfere with MeHg's effects on the hematological parameters assessed. Mean corpuscular hemoglobin concentration (MCHC) was significantly decreased following exposure to antibiotics and in all treatment groups exposed to $\mathrm{MeHg}$ (Table 2). The expected increases in serum IgE levels [30, 31] were observed in all $\mathrm{MeHg}$-treated rats, while a modest increase in IgG concentration of dubious biological relevance was observed in the MeHg + Labrador Tea treatment group (Table 2).

Rats from the antibiotics treatment group presented significantly higher blood and kidney mercury levels than those observed in the control group (Table 3). In $\mathrm{MeHg}$-treated rats, co-exposure to antibiotics resulted in lower feces and higher blood mercury levels. Contrastingly, mercury levels measured in the Labrador Tea and
$\mathrm{MeHg}+$ Labrador Tea treatment groups were undistinguishable from those observed in the control or $\mathrm{MeHg}$ treatment groups, respectively (Table 3).

\section{Discussion}

Information on the modulation of $\mathrm{MeHg}$ toxicokinetics by dietary phytochemicals in human is scarce, especially for Arctic populations [32, 33]. In a controlled exposure study, tea consumption was associated with higher blood mercury levels in volunteers who ate fish [22], while higher maternal blood mercury levels were associated with herbal tea consumption in a large British birth cohort study [1]. In rodents, similarly to our previous work on perinatal co-exposure to $\mathrm{MeHg}$ and Labrador Tea [23], other investigators reported that co-administration of green tea extract to fish-fed rats led to higher blood mercury levels [34], and that mice co-exposed to green tea extract and $\mathrm{MeHg}$ presented higher muscle mercury levels than mice exposed to $\mathrm{MeHg}$ alone [35]. Together, these investigations suggest that dietary phytochemicals may interfere with $\mathrm{MeHg}$ absorption, distribution, metabolism and excretion.

In the current study, MeHg, Labrador Tea and antibiotics administered either alone or in combination, did not affect rat bodyweight gains (Table 1) or cause overt toxicity over the exposure period. They also had limited effects on the hematological parameters assessed (Table 2). Hence, indirect effects resulting from severe toxicity are unlikely to have interfered with $\mathrm{MeHg}$ absorption, distribution, metabolism and excretion. Gamma glutamyl transferase (GGT) activity, which is involved in the biliary metabolism of $\mathrm{MeHg}$-glutathione conjugate to the more easily reabsorbed $\mathrm{MeHg}$-cysteine [13], was not significantly affected by any of the treatment groups (Table 1). Despite in vitro data suggesting

Table 1 Effects of treatments on rat bodyweight gains, organ weights and liver enzymatic activities

\begin{tabular}{|c|c|c|c|c|c|c|}
\hline & Control & Labrador Tea & Antibiotics & $\mathrm{MeHg}$ & MeHg + Labrador Tea & MeHg + antibiotics \\
\hline Body weight gain (g) & $78.0 \pm 15.6$ & $84.4 \pm 8.0$ & $82.9 \pm 17.1$ & $75.3 \pm 22.1$ & $75.7 \pm 20.8$ & $76.8 \pm 21.2$ \\
\hline Kidney weight, absolute (g) & $2.20 \pm 0.25$ & $2.25 \pm 0.24$ & $2.24 \pm 0.25$ & $2.35 \pm 0.22$ & $2.41 \pm 0.13$ & $2.25 \pm 0.26$ \\
\hline Kidney weight, relative (\%) & $0.609 \pm 0.029$ & $0.606 \pm 0.028$ & $0.613 \pm 0.029$ & $0.657 \pm 0.042$ & $0.659 \pm 0.055$ & $0.615 \pm 0.050$ \\
\hline Liver weight, absolute (g) & $12.64 \pm 2.42$ & $12.98 \pm 0.88$ & $10.60 \pm 1.37$ & $11.78 \pm 1.06$ & $12.44 \pm 1.88$ & $10.32 \pm 1.34^{*}$ \\
\hline Liver weight, relative (\%) & $3.50 \pm 0.17$ & $3.50 \pm 0.16$ & $2.89 \pm 0.17^{*}$ & $3.29 \pm 0.19$ & $3.37 \pm 0.23$ & $2.81 \pm 0.16^{*}$ \\
\hline \multicolumn{7}{|l|}{ Liver enzymatic activities } \\
\hline BROD (pmol/min/mg prot) & $42.7 \pm 18.7$ & $88.6 \pm 26.3$ & $105.5 \pm 49.1^{*}$ & $62.2 \pm 23.4$ & $84.0 \pm 41.4$ & $103.2 \pm 36.3^{*}$ \\
\hline EROD (pmol/min/mg prot) & $54.1 \pm 24.4$ & $88.4 \pm 22.5$ & $93.4 \pm 37.6^{*}$ & $28.0 \pm 18.6$ & $63.8 \pm 28.4$ & $69.4 \pm 21.7$ \\
\hline PROD (pmol/min/mg prot) & $17.3 \pm 7.0$ & $30.0 \pm 8.8$ & $33.5 \pm 13.1^{*}$ & $16.6 \pm 6.9$ & $19.5 \pm 10.0$ & $22.1 \pm 8.8$ \\
\hline GGT (mU/g prot) & $93.7 \pm 51.0$ & $113.2 \pm 34.0$ & $146.1 \pm 30.1$ & $102.9 \pm 76.9$ & $100.1 \pm 32.5$ & $79.8 \pm 33.2$ \\
\hline
\end{tabular}

Mean \pm SD of seven animals per treatment group

EROD: ethoxyresorufin-O-deethylase; BROD: benzyloxyresorufin-O-dealkylase; PROD: pentoxyresorufin-O-dealkylase; GGT: gamma glutamyl transferase

* Significantly different from control group values $(P<0.05)$ as assessed by one-way ANOVA followed by Dunnett post hoc test 
Table 2 Effects of treatments on rat hematological parameters

\begin{tabular}{|c|c|c|c|c|c|c|}
\hline & Control & Labrador Tea & Antibiotics & $\mathrm{MeHg}$ & MeHg + Labrador Tea & MeHg + antibiotics \\
\hline $\mathrm{RBC}\left(\times 10^{6}\right.$ cells $\left./ \mu \mathrm{L}\right)$ & $7.54 \pm 0.46$ & $7.59 \pm 0.15$ & $7.93 \pm 0.32$ & $7.83 \pm 0.32$ & $7.86 \pm 0.29$ & $7.75 \pm 0.37$ \\
\hline $\mathrm{HGB}(\mathrm{g} / \mathrm{dL})$ & $14.36 \pm 0.49$ & $14.11 \pm 0.34$ & $14.37 \pm 0.43$ & $14.39 \pm 0.29$ & $14.37 \pm 0.61$ & $14.33 \pm 0.54$ \\
\hline НCT (\%) & $42.31 \pm 1.95$ & $42.01 \pm 1.50$ & $43.50 \pm 1.08$ & $43.84 \pm 1.35$ & $43.67 \pm 1.92$ & $43.57 \pm 1.82$ \\
\hline $\mathrm{MCV}(\mathrm{fL})$ & $56.20 \pm 1.10$ & $55.36 \pm 1.18$ & $54.95 \pm 1.42$ & $56.03 \pm 1.77$ & $55.53 \pm 1.69$ & $56.24 \pm 2.00$ \\
\hline $\mathrm{MCH}(\mathrm{pg})$ & $19.07 \pm 0.70$ & $18.59 \pm 0.31$ & $18.18 \pm 0.43$ & $18.4 \pm 0.59$ & $18.28 \pm 0.48$ & $18.46 \pm 0.59$ \\
\hline $\mathrm{MCHC}(\mathrm{g} / \mathrm{dL})$ & $33.94 \pm 0.72$ & $33.59 \pm 0.54$ & $33.03 \pm 0.64^{*}$ & $32.83 \pm 0.63^{*}$ & $32.88 \pm 0.58^{*}$ & $32.86 \pm 0.32^{*}$ \\
\hline PLT $\left(\times 10^{3}\right.$ cells $\left./ \mu \mathrm{L}\right)$ & $867 \pm 138$ & $1010 \pm 68^{*}$ & $921 \pm 84$ & $977 \pm 45$ & $969 \pm 62$ & $875 \pm 159$ \\
\hline MPV (fL) & $6.03 \pm 1.29$ & $6.04 \pm 1.11$ & $6.08 \pm 1.34$ & $6.20 \pm 1.08$ & $6.40 \pm 1.38$ & $6.20 \pm 1.37$ \\
\hline WBC $\left(\times 10^{3}\right.$ cells $\left./ \mu \mathrm{L}\right)$ & $4.25 \pm 1.57$ & $4.62 \pm 0.39$ & $3.86 \pm 1.50$ & $5.79 \pm 1.72$ & $5.13 \pm 1.4$ & $4.24 \pm 1.10$ \\
\hline 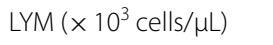 & $3.21 \pm 1.63$ & $3.79 \pm 0.37$ & $3.26 \pm 1.47$ & $4.35 \pm 1.53$ & $3.92 \pm 1.25$ & $3.32 \pm 0.75$ \\
\hline NEUT ( $\times 10^{3}$ cells $\left./ \mu \mathrm{L}\right)$ & $0.57 \pm 0.46$ & $0.41 \pm 0.25$ & $0.30 \pm 0.19$ & $0.78 \pm 0.90$ & $0.5 \pm 0.36$ & $0.23 \pm 0.16$ \\
\hline MONO ( $\times 10^{3}$ cells $\left./ \mu \mathrm{L}\right)$ & $0.23 \pm 0.22$ & $0.22 \pm 0.31$ & $0.12 \pm 0.12$ & $0.32 \pm 0.37$ & $0.36 \pm 0.39$ & $0.29 \pm 0.29$ \\
\hline $\operatorname{EOS}\left(\times 10^{3}\right.$ cells $\left./ \mu \mathrm{L}\right)$ & $0.041 \pm 0.018$ & $0.040 \pm 0.008$ & $0.040 \pm 0.030$ & $0.049 \pm 0.020$ & $0.073 \pm 0.077$ & $0.053 \pm 0.027$ \\
\hline LUC $\left(\times 10^{3}\right.$ cells $\left./ \mu \mathrm{L}\right)$ & $0.17 \pm 0.14$ & $0.14 \pm 0.17$ & $0.12 \pm 0.12$ & $0.25 \pm 0.32$ & $0.23 \pm 0.25$ & $0.30 \pm 0.34$ \\
\hline BASO $\left(\times 10^{3}\right.$ cells $\left./ \mu \mathrm{L}\right)$ & $0.03 \pm 0.01$ & $0.02 \pm 0.00$ & $0.03 \pm 0.01$ & $0.04 \pm 0.02$ & $0.03 \pm 0.01$ & $0.03 \pm 0.02$ \\
\hline LYM (\%) & $73.26 \pm 13.50$ & $82.01 \pm 5.09$ & $82.28 \pm 7.63$ & $75.09 \pm 12.07$ & $76.03 \pm 5.22$ & $79.13 \pm 7.07$ \\
\hline NEUT (\%) & $14.56 \pm 12.89$ & $9.06 \pm 5.73$ & $8.33 \pm 5.30$ & $14.09 \pm 14.28$ & $10.42 \pm 7.35$ & $6.16 \pm 4.49$ \\
\hline MONO (\%) & $6.11 \pm 6.35$ & $4.64 \pm 6.40$ & $3.65 \pm 4.75$ & $5.24 \pm 5.68$ & $7.05 \pm 7.82$ & $6.31 \pm 5.33$ \\
\hline EOS (\%) & $1.04 \pm 0.46$ & $0.90 \pm 0.21$ & $1.08 \pm 0.73$ & $0.91 \pm 0.51$ & $1.58 \pm 1.83$ & $1.34 \pm 0.57$ \\
\hline LUC (\%) & $4.36 \pm 3.93$ & $2.96 \pm 3.35$ & $3.73 \pm 4.81$ & $4.07 \pm 5.04$ & $4.33 \pm 4.4$ & $6.21 \pm 6.14$ \\
\hline BASO (\%) & $0.66 \pm 0.32$ & $0.43 \pm 0.10$ & $0.93 \pm 0.79$ & $0.61 \pm 0.21$ & $0.63 \pm 0.18$ & $0.89 \pm 0.50$ \\
\hline $\operatorname{lgG}(\mathrm{mg} / \mathrm{mL})$ & $2.57 \pm 0.93$ & $3.42 \pm 0.93$ & $2.77 \pm 0.97$ & $3.48 \pm 1.71$ & $5.48 \pm 2.21^{\#}$ & $2.89 \pm 1.62$ \\
\hline $\operatorname{lgM}(\mu \mathrm{g} / \mathrm{mL})$ & $108.2 \pm 38.9$ & $94.8 \pm 21.9$ & $84.1 \pm 18.7$ & $218.4 \pm 303.5$ & $107 \pm 18.3$ & $85.9 \pm 29.8$ \\
\hline $\lg A(\mu \mathrm{g} / \mathrm{mL})$ & $22.7 \pm 3.4$ & $24.7 \pm 2.6$ & $24.9 \pm 12.0$ & $18.7 \pm 2.7$ & $38.2 \pm 11.7$ & $22.4 \pm 3.2$ \\
\hline $\lg \mathrm{E}(\mathrm{ng} / \mathrm{mL})$ & $9.2 \pm 9.1$ & $14.5 \pm 26.1$ & $6.3 \pm 6.1$ & $240.3 \pm 263.6^{*}$ & $410.1 \pm 266.7^{*}$ & $115.9 \pm 199.3^{*}$ \\
\hline
\end{tabular}

Mean \pm SD of 6-7 animals per treatment group

RBC: red blood cells; HGB: hemoglobin; HCT: hematocrit; MCV: mean corpuscular volume; $\mathrm{MCH}$ : mean corpuscular hemoglobin; MCHC: mean corpuscular hemoglobin concentration; PLT: platelet; MPV: mean platelet volume; WBC: white blood cells; LYM: lymphocytes; NEUT: neutrophils; MONO, monocytes; EOS: eosinophils; LUC: large unstained cells; BASO: basophils

* Significantly different from control group values $(P<0.05)$ as assessed by one-way ANOVA followed by Dunnett post hoc test

\# Significantly different from control group values $(P<0.05)$ as assessed by Kruskal-Wallis ANOVA followed by Dunnett post hoc test on ranks

Table 3 Total mercury concentrations measured in rat blood and lyophilized liver, kidney and feces

\begin{tabular}{lcccccc}
\hline & Control & Labrador Tea & Antibiotics & MeHg & MeHg+ Labrador Tea & MeHg+antibiotics \\
\hline Blood (ppm) & $0.0231 \pm 0.0035$ & $0.0262 \pm 0.0019$ & $0.0441 \pm 0.0080^{*}$ & $76.4 \pm 6.5$ & $74.9 \pm 10.5$ & $98.1 \pm 18.0^{*}$ \\
Liver (ppm) & $0.0235 \pm 0.0028$ & $0.0238 \pm 0.0122$ & $0.0348 \pm 0.0068$ & $53.1 \pm 5.0$ & $50.7 \pm 13.2$ & $45.5 \pm 7.0$ \\
Kidney (ppm) & $0.189 \pm 0.027$ & $0.202 \pm 0.027$ & $0.353 \pm 0.055^{*}$ & $343.1 \pm 24.5$ & $334.8 \pm 57.7$ & $325.3 \pm 48.9$ \\
Feces (ppm) & $0.0208 \pm 0.0090$ & $0.0177 \pm 0.0014$ & $0.018 \pm 0.010$ & $16.4 \pm 4.3$ & $15.7 \pm 3.5$ & $5.4 \pm 0.7^{*}$ \\
\hline
\end{tabular}

Mean \pm SD of 6-7 animals per treatment group

* Significantly different from control group or MeHg treatment group values $(P<0.05)$ as assessed by one-way ANOVA followed by Dunnett post hoc test

that Labrador Tea may affect cytochrome p450 activities [36], no statistically significant perturbation of liver enzymatic activities (Table 1) was observed following exposure to Labrador Tea at a concentration previously shown to affect oxidative stress biomarkers and blood $\mathrm{MeHg}$ levels in developing rat pups [23].
As expected, co-administration of $\mathrm{MeHg}$ and antibiotics resulted in lower fecal excretion rates and higher blood mercury levels compared to rats exposed to $\mathrm{MeHg}$ alone (Table 3). In rats that were not exposed to $\mathrm{MeHg}$, the antibiotics treatment group also presented higher blood mercury levels compared to the control group. At 
background mercury exposure levels, $\mathrm{MeHg}$ represents a comparatively smaller fraction of the total mercury measured in rats [23]. This may explain why fecal mercury excretion (which is influenced by $\mathrm{MeHg}$ demethylation [15-17]) was not significantly affected, while kidneys (which preferentially accumulate inorganic mercury [37]) presented significantly higher mercury levels in the antibiotics treatment group.

Contrary to our previous rat perinatal $\mathrm{MeHg}$ co-exposure study where Labrador Tea significantly affected blood mercury levels in both male and female pups [23], co-administration of Labrador Tea had no effect on mercury body burden or excretion in adult male rats (Table 3). This observation may reflect genuine differences between juvenile and adult rats in the absorption, distribution, metabolism and excretion of $\mathrm{MeHg}$. Alternatively, rat pups are acutely sensitive to $\mathrm{MeHg}$ toxicity and high mortality rates were observed in developmentally exposed pups [23]. The mitigation of $\mathrm{MeHg}$ induced oxidative stress and excitotoxicity by Labrador Tea observed in this previous study may therefore have resulted in the improved survival of rats pups presenting higher mercury body burdens, compared to pups exposed to MeHg alone [23].

Although Labrador Tea consumption is limited to small Northern/Arctic populations, the most abundant phytochemicals identified in $R$. tomentosum extract, namely quercetin, cachetins, chlorogenic acid and caffeic acid [24], are commonly found in various other food sources and can be purchased as dietary supplements. While we were able to clearly observe the effects of antibiotics treatment, we failed to detect any significant effect of Labrador Tea co-exposure on mercury fecal excretion and body burden in adult male rats. This observation is at odds with our previous Labrador Tea co-exposure study in rats pups [23] and with other $\mathrm{MeHg}$ and tea co-exposure studies in rodents [34, 35] and humans [22]. However, in light of the well-known literature bias towards positive results [38], it is nevertheless important to report such negative findings.

\section{Limitations}

Although the lower fecal excretion rates and higher blood mercury levels observed in antibiotics-treated rats were attributed to the inhibition of $\mathrm{MeHg}$ demethylation by gut bacteria, other mechanisms such as perturbation of enzymatic activities in the liver (Table 1) or in other tissues, and alteration of gut barrier permeability [39] may also have contributed to these observations. Likewise, phytochemicals may also affect $\mathrm{MeHg}$ toxicokinetics through similar mechanisms, in addition to modulation of gut microbiota [19-21] and $\mathrm{MeHg}$ chelation $[9,11,40]$. Generalization of our conclusions to other teas, fruits and vegetables should be avoided, as phytochemicals absent from Labrador Tea but present in other herbal decoctions, and dietary fibers in fruits and vegetables may affect $\mathrm{MeHg}$ absorption, distribution, metabolism and excretion [11, 41]. Finally, we cannot rule out that a different choice of exposure and experimental protocols may have allowed the observation of subtler effects.

\section{Additional file}

Additional file 1. Additional file contains all the raw data on rat body weight gains, organ weights, hematology, antibody isotyping, liver functions and mercury quantification presented in this manuscript.

\section{Abbreviations}

ANOVA: analysis of variance; BASO: basophils; BROD: benzyloxyresorufinO-dealkylase; EOS: eosinophils; EROD: ethoxyresorufin-O-deethylase; GGT: gamma glutamyl transferase; HCT: hematocrit; HGB: hemoglobin; ICP-MS: inductively-coupled plasma mass spectrometry; IgA: immunoglobulin A; lgE: immunoglobulin E; IgG: immunoglobulin G; IgM: immunoglobulin M; LUC: large unstained cells; LYM: lymphocytes; MCH: mean corpuscular hemoglobin; MCHC: mean corpuscular hemoglobin concentration; MCV: mean corpuscular volume; MeHg: methylmercury; MONO: monocytes; MPV: mean platelet volume; NEUT: neutrophils; PLT: platelet; PROD: pentoxyresorufin-O-dealkylase; RBC: red blood cells; SD: standard deviation; WBC: white blood cells.

\section{Acknowledgements}

The authors want to thank Drs. Andy Nong and Philip Shwed for their helpful comments on this manuscript.

\section{Authors' contributions}

GP designed the study, dosed the rats, analysed the data and wrote the manuscript. PB harvested R. tomentosum samples, performed the ethanolic extraction and characterized the resulting Labrador Tea extract. Y-LF was involved in mercury quantification. KL measured liver enzymatic activities and hematological parameters. All authors read and approved the final manuscript.

\section{Funding}

This work was funded by Health Canada's Chemicals Management Plan (CMP), which had no role in the design of the study, in the collection and analysis of data, and in the preparation of the manuscript.

\section{Availability of data and materials}

The raw data for this manuscript are included in Additional file 1.

\section{Ethics approval and consent to participate}

The animal study protocol was performed according to the guidelines of the Canadian Council on Animal Care and approved by the Health Canada Animal Care Committee prior to the initiation of the study.

\section{Consent for publication}

Not applicable.

\section{Competing interests}

The authors declare that they have no competing interests.

\section{Author details}

${ }^{1}$ Hazard Identification Division, Environmental Health Science and Research Bureau, Health Canada, Environmental Health Centre, 50 Colombine Driveway, P.L. 0803B, Tunney's Pasture, Ottawa, ON K1A 0K9, Canada. ${ }^{2}$ Exposure and Biomonitoring Division, Environmental Health Science and Research Bureau, Health Canada, Ottawa, ON, Canada. ${ }^{3}$ Department of Biology, University of Ottawa, Ottawa, ON, Canada. 
Received: 18 January 2019 Accepted: 26 June 2019

Published online: 01 July 2019

\section{References}

1. Golding J, Steer CD, Hibbeln JR, Emmett PM, Lowery T, Jones R. Dietary predictors of maternal prenatal blood mercury levels in the ALSPAC birth cohort study. Environ Health Perspect. 2013;121:1214-8.

2. Yaginuma-Sakurai K, Shimada M, Ohba T, Nakai K, Suzuki K, Kurokawa N, et al. Assessment of exposure to methylmercury in pregnant Japanese women by FFQ. Public Health Nutr. 2009;12:2352-8.

3. Yaginuma-Sakurai K, Murata K, Iwai-Shimada M, Nakai K, Kurokawa N, Tatsuta N, et al. Hair-to-blood ratio and biological half-life of mercury: experimental study of methylmercury exposure through fish consumption in humans. J Toxicol Sci. 2012;37:123-30.

4. Lin Y, Ginsberg G, Caffrey JL, Xue J, Vulimiri SV, Nath RG, et al. Association of body burden of mercury with liver function test status in the US population. Environ Int. 2014;70:88-94.

5. Sheehan MC, Burke TA, Breysse PN, Navas-Acien A, McGready J, Fox MA. Association of markers of chronic viral hepatitis and blood mercury levels in US reproductive-age women from NHANES 2001-2008: a cross-sectional study. Environ Health. 2012;11:62.

6. Ha E, Basu N, Bose-O'Reilly S, Dórea JG, McSorley E, Sakamoto M, et al. Current progress on understanding the impact of mercury on human health. Environ Res. 2017;152:419-33.

7. Basu N, Goodrich JM, Head J. Ecogenetics of mercury: from genetic polymorphisms and epigenetics to risk assessment and decision-making. Environ Toxicol Chem. 2014;33:1248-58.

8. Ouédraogo $\mathrm{O}$, Amyot M. Effects of various cooking methods and food components on bioaccessibility of mercury from fish. Environ Res. 2011;111:1064-9.

9. Girard C, Charette T, Leclerc M, Shapiro BJ, Amyot M. Cooking and co-ingested polyphenols reduce in vitro methylmercury bioaccessibility from fish and may alter exposure in humans. Sci Total Environ. 2018;616:863-74.

10. Chapman L, Chan HM. The influence of nutrition on methyl mercury intoxication. Environ Health Perspect. 2000;108(Suppl 1):29-56.

11. Shim SM, Ferruzzi MG, Kim YC, Janle EM, Santerre CR. Impact of phytochemical-rich foods on bioaccessibility of mercury from fish. Food Chem. 2009; 112:46-50.

12. Jadán-Piedra C, Chiocchetti GM, Clemente MJ, Vélez D, Devesa V. Dietary compounds as modulators of metals and metalloids toxicity. Crit Rev Food Sci Nutr. 2017;58:2055-67.

13. Dutczak WJ, Ballatori N. gamma-Glutamyltransferase-dependent biliaryhepatic recycling of methyl mercury in the guinea pig. J Pharmacol Exp Ther. 1992;262:619-23.

14. Farris F, Dedrick R, Allen P, Smith JC. Physiological model for the pharmacokinetics of methyl mercury in the growing rat. Toxicol Appl Pharmacol. 1993; 119:74-90.

15. Nakamura I, Hosokawa K, Tamura H, Miura T. Reduced mercury excretion with feces in germfree mice after oral administration of methyl mercury chloride. Bull Environ Contam Toxicol. 1977;17:528-33.

16. Rowland IR. Interactions of the gut microflora and the host in toxicology. Toxicol Pathol. 1988;16:147-53.

17. Seko Y, Miura T, Takahashi M, Koyama T. Methyl mercury decomposition in mice treated with antibiotics. Basic Clin Pharmacol Toxicol. 1981;49:259-65.

18. Wu GD, Chen J, Hoffmann C, Bittinger K, Chen YY, Keilbaugh SA, et al. Linking long-term dietary patterns with gut microbial enterotypes. Science. 2011;334:105-8.

19. Cueva C, Moreno-Arribas MV, Martín-Álvarez PJ, Bills G, Vicente MF, Basilio A, et al. Antimicrobial activity of phenolic acids against commensal, probiotic and pathogenic bacteria. Res Microbiol. 2010;161:372-82.

20. Yam T, Shah S, Hamilton-Miller J. Microbiological activity of whole and fractionated crude extracts of tea (Camellia sinensis), and of tea components. FEMS Microbiol Lett. 1997;152:169-74.

21. Mai V, Katki HA, Harmsen H, Gallaher D, Schatzkin A, Baer DJ, et al. Effects of a controlled diet and black tea drinking on the fecal microflora composition and the fecal bile acid profile of human volunteers in a doubleblinded randomized feeding study. J Nutr. 2004;134:473-8.
22. Canuel R, de Grosbois SB, Lucotte M, Atikessé L, Larose C, Rheault I. New evidence on the effects of tea on mercury metabolism in humans. Arch Environ Occup Health. 2006;61:232-8.

23. Black P, Niu L, Sachdeva M, Lean D, Poon R, Bowers WJ, et al. Modulation of the effects of methylmercury on rat neurodevelopment by co-exposure with Labrador Tea (Rhododendron tomentosum ssp. subarcticum). Food Chem Toxicol. 2011;49:2336-42.

24. Black P, Saleem A, Dunford A, Guerrero-Analco J, Walshe-Roussel B, Haddad $\mathrm{P}$, et al. Seasonal variation of phenolic constituents and medicinal activities of Northern Labrador tea, Rhododendron tomentosum ssp. subarcticum, an Inuit and Cree First Nations traditional medicine. Planta Med. 2011;77:1655-62.

25. Poon R, Valli V, Rigden M, Rideout G, Pelletier G. Short-term oral toxicity of three biodiesels and an ultra-low sulfur diesel in male rats. Food Chem Toxicol. 2009;47:1416-24.

26. Poon R, Valli V, Ratnayake W, Rigden M, Pelletier G. Effects of Jatropha oil on rats following 28-day oral treatment. J Appl Toxicol. 2013;33:618-25.

27. Waldner $\mathrm{CL}$, Blakley B. Evaluating micronutrient concentrations in liver samples from abortions, stillbirths, and neonatal and postnatal losses in beef calves. J Vet Diagn Invest. 2014;26:376-89.

28. Pollock B, Machin KL. Corticosterone in relation to tissue cadmium, mercury and selenium concentrations and social status of male lesser scaup (Aythya affinis). Ecotoxicology. 2009;18:5-14.

29. Solleveld HA, Boorman GA. Spontaneous renal lesions in five rat strains. Toxicol Pathol. 1986;14:168-74.

30. Häggqvist B, Havarinasab S, Björn E, Hultman P. The immunosuppressive effect of methylmercury does not preclude development of autoimmunity in genetically susceptible mice. Toxicology. 2005;208:149-64.

31. Prouvost-Danon A, Abadie A, Sapin C, Bazin H, Druet P. Induction of IgE synthesis and potentiation of anti-ovalbumin IgE antibody response by $\mathrm{HgCl} 2$ in the rat. J Immunol. 1981;126:699-792.

32. Gagné D, Lauzière J, Blanchet R, Vézina C, Vaissière É, Ayotte P, et al. Consumption of tomato products is associated with lower blood mercury levels in Inuit preschool children. Food Chem Toxicol. 2013;51:404-10.

33. Airaksinen R, Turunen AW, Rantakokko P, Männistö S, Vartiainen T, Verkasalo PK. Blood concentration of methylmercury in relation to food consumption. Public Health Nutr. 2011;14:480-9.

34. Janle EM, Freiser H, Manganais C, Chen TY, Craig BA, Santerre CR. Green tea increases the concentration of total mercury in the blood of rats following an oral fish tissue bolus. Biomed Res Int. 2015;2015:320936.

35. Shirai N, Yamashita Y, Yamashita M. Simultaneous effects of green tea extracts and fish oil on mercury accumulation and antioxidant defenses in methylmercury-exposed adult mice. Food Sci Technol Res. 2013;19:883-91.

36. Tam TW, Liu R, Arnason JT, Krantis A, Staines WA, Haddad PS, et al. Actions of ethnobotanically selected Cree anti-diabetic plants on human cytochrome P450 isoforms and flavin-containing monooxygenase 3. J Ethnopharmacol. 2009;126:119-26.

37. Zalups RK. Molecular interactions with mercury in the kidney. Pharmacol Rev. 2000;52:113-43.

38. Song F, Parekh-Bhurke S, Hooper L, Loke YK, Ryder JJ, Sutton AJ, et al. Extent of publication bias in different categories of research cohorts: a meta-analysis of empirical studies. BMC Med Res Methodol. 2009:9:79.

39. Rothenberg SE, Keiser S, Ajami NJ, Wong MC, Gesell J, Petrosino JF, et al. The role of gut microbiota in fetal methylmercury exposure: insights from a pilot study. Toxicol Lett. 2016;242:60-7.

40. Torres J, Olivares S, Rosa DL, Lima L, Martinez F, Munita CS, et al. Removal of mercury (II) and methylmercury from solution by tannin adsorbents. J Radioanal Nucl Chem. 1999;240:361-5.

41. Kachenpukdee N, Santerre CR, Ferruzzi MG, Oonsivilai R. Modified dietary fiber from cassava pulp and assessment of mercury bioaccessibility and intestinal uptake using an in vitro digestion/Caco-2 Model System. J Food Sci. 2016;81:T1854-63.

\section{Publisher's Note}

Springer Nature remains neutral with regard to jurisdictional claims in published maps and institutional affiliations. 